\title{
UMA PROPOSTA DE REFORMA: UM DIVIDENDO GLOBAL DE RECURSOS*
}

THOMAS POGGE

A extensão e a severidade da pobreza mundial representam hoje um grande desafio para qualquer pessoa com sensibilidade moral. Estamos diante de centenas de milhões de pessoas que nasceram na mais abjeta pobreza em algum lugar do assim chamado Terceiro Mundo e que passam toda sua vida em condiçôes de pobreza extrema: dependentes, analfabetas e esquálidas. ${ }^{1}$ Essas pessoas são tão pobres e tão privadas de nutriçăo, higiene e remédios adequados que cerca de 20 milhões delas morrem rotineiramente a cada ano de doenças facilmente curáveis. ${ }^{2}$ Sua condição contrasta com a de muitos outros que são imensamente mais privilegiados com respeito a quase todos os aspectos interpessoalmente variáveis da vida humana, tais como: segurança pessoal, direitos, liberdade e oportunidades; influência política; renda, riqueza e tempo de lazer; saneamento e

\footnotetext{
* "A Global Resources Dividend". Tradução da Álvaro de Vita.

10 Programa de Desenvolvimento das Nạ̧őes Unidas (PDNU) registra algo como 1,3 bilhão de pessoas pobres nos anos 80, das quais 350 milhões ( $40 \%$ da população) estāo na Índia, 105 milhōes ( $10 \%$ da população) cstão na China, 93 milhōes ( $80 \%$ ) em Bangladesh, 72 milhōes (47\%) no Brasil e perto de 300 milhŏes na Etiópia, no Vietnă, nas Filipinas, na Nigéria, Paquistão e na Indonésia (The Economist, 25/6/1994, p. 130). Cito estes números para dar uma idéia aproximada das pessoas a respeito das quais refletiremos. Mas para os nossos propósitos no momento, possíveis discordâncias com respeito à definição de pobreza do PDNU nạo vem ao caso, desde que se concorde que há muitas pessoas desesperadamente pobres.

2 Somente uma pequena parte dessas mortes ocorrem etn fomes e outras catístrofes concentradas (e bastante noticiadas), tais como os ciclones, os terremotos e o recente êxodo de Ruanda. A maior parte dessas mortes ocorrem em períodos normais, em meio à prosperidade, lá onde a pobreza torna as pessoas altamente vulneráveis até́ mesmo a pequenos infortúnios. Por ser temporal e espacialmente disperso, esse sofrimento - apesar de igualmente catastrófico - recebe bem pouca atençăo.
} 
higiene; expectativa de vida e mortalidade infantil; acesso à educação, assistência médica, alimentação, vestuário e habitação. É difícil quantificar algumas dessas desigualdades. Mas mesmo uma passada de olhos somente nas médias nacionais já oferece uma percepção de sua magnitude: a variação no PIB per capita é de 100:1, e os diferenciais nacionais de renda per capita são ainda muito maiores. ${ }^{3}$

Enquanto um desafio moral a nós colocado, essas privaçōes podem ser concebida de duas formas. Podemos imaginar que elas nos dirigem um apelo de natureza ética - pedindo-nos, uma vez que os pobres realmente padecem e que nos encontramos em uma situação tão melhor do que a deles, que sacrifiquemos parte de nosso tempo, energia e recursos para melhorar sua condiçăo. Diferentemente, podemos imaginar que essas privações apelem para nós em termos de justiça - apresentando o sofrimento e a inferioridade dos pobres como uma injustiça que lhes é imposta pela ação humana e mostrando-nos como os que contribuem para essa imposição, ou dela beneficiam-se, injustamente.

As duas visőes diferem em aspectos importantes. $\mathrm{O}$ apelo à ética é, em geral, muito mais aplicável e, por isso, consegue pleitear sua relevância mais facilmente. Somente é preciso mostrar a miserabilidade dos pobres, a situaçẩo muito melhor em que nos encontramos, e que temos como aliviar parte de seu sofrimento sem que isso signifique uma redução significativa em nosso próprio padrão de vida. Mas isso tem un preço: muitas pessoas que reconhecem a validade do apelo ético sentem-se no direito, a despeito disso, de se concentrarem en viver a própria vida nenhuma preocupação com as causas nobres às quais poderiam devotar seus recursos. No mínimo, elas se sentem no direito de apoiarem as boas causas de sua própria escolha - talvez a sua igreja, o conselho local de moradores, a sua alma mater, ou então a pesquisa médica, os direitos dos animais ou a proteção ambiental -, ao invés de se sacrificareın por estranhos que vivem meio mundo distante, com os quais não têm quaisquer vínculos, ademais daquele muito tênue de uma humanidade conım, de comunidade ou de cultura.

${ }^{3}$ Apesar de ser importante para o meu argumento o fato de que somos (nós, dos países desenvolvidos) abastados e de encontramo-nos em uma situaçio muito melhor do que os pobres do mundo, nāo discutirei a definiçî́o e a cspecificaaçāo de uma medida de qualidade de vida. Esta questão tem recebido, recentemente, uma considerável atenção acadêmica e mais destacadamente, talvez, por Ronald Dworkin, James Griffin, Martha Nussbaum, Derek Parfit, Johu Rawls, Thomas Scanlon c Amartya Sen. Passo por alto pela questăo por não ter como enfrentá-la aproptiadamente no monvento e também porque qualquer especificaçẫo plausivel da qualidade de vida reforçaria, acredito, os argumentos que desenvolverci. Toda essa discussão, além disso, no momento poderia confundir nossa apreciaçũo daquilo que deve ser visto como um fato avassaladoramente óbvio e monstruoso. 
Este ensaio enfoca o apelo à justiça. Tentarei mostrar que a organização vigente das instituições econômicas mundiais, com a distribuição de benefícios e de encargos que ela engendra, é injusta e que temos que reformá-la na direção de uma alternativa institucional sob a qual a posição daqueles em pior situação seria muito melhorada em termos tanto absolutos quanto relativos (e a nossa própria posição [nos países ricos] provavelmente pioraria em termos relativos e talvez mesno em termos absolutos). De forma prévia à realização de semelhante proposta, devemos tentar proteger as vítimas das instituições injustas existentes - pelo menos na medida em que é possível fazê-lo por meio de benefícios que, sob instituições justas, não esperaríamos poder controlar.

Ao substanciar minha proposta, evitarei falar de sacrifício, de socorro, e coisas do gênero, para enfatizar as diferenças entre os meus argumentos e o enfoque ético. Eu realmente defendo que empreendamos projetos de reforma e de proteção que beneficiariam os pobres globais projetos que eles não podem nos forçar a colocar em prática e que reduziriam nossas vantagens. Falar de sacrifício e de socorro, entretanto, pode sugerir que esses projetos såo também moralmente opcionais - um bem entre muitos outros, que se deve apoiar ou não conforme se julgue ser melhor. E isso eu nego: não contribuir para a reduçăo e a erradicaçăo das privações do Terceiro Mundo é um grave equívoco. É claro que, se esses projetos forem bem-sucedidos, eles ajudarão, em certo sentido, os pobres globais. Contudo, interpreta-se melhor o objetivo como sendo o de emancipá-los ou libertá-los de sua condição opressiva, assim como o objetivo abolicionista é melhor interpretado não como uma ajuda e sim como uma emancipação ou uma libertação dos escravos.

O apelo à justiça leva a conclusōes muito mais rigorosas e potentes to que o apelo à ética. O primeiro supōe que compartilhamos de uma real responsabilidade pela pobreza global — um dever negativo de näo seguir impondo, disso tirando partido, instituições econômicas globais injustas - , e não meramente de um dever positivo de ajudar aqueles que são mais desvalidos do que nós. Por isso, é um apelo que pode atingire influenciar mesmo os mais endurecidos ... tais como Charles Darwin, por exemplo, que escreveu sobre a pobreza de seu país: "se a miséria de nossos pobres é causada não por leis da natureza, mas por nossas próprias instituições, maior é o nosso pecado".5 De outra parte, um apelo à justiça, para ser plausível, deve também sa-

4 Discuti mais detalhadamente essa distinçäo entre deveres positivos (mais fracos) e deveres negativos (mais rigorosos) em Realizing Rawls (Ithaca, Cornell University Press, 1989), pp. 17 e 5., p. 27 c em "Cosmopolitanism and Sovereignty", Ethics 103, 1993, p.56.

5 Citado por Stephen Jay Gould em "The Moral State of Tahiti - and of Darwin". Natural History 10/91, 12-19, p.194. 
tisfazer padrōes muito mais estritos. Não basta dizer que há pessoas que estão em uma péssima situação e que poderíamos melhorar suas condições a um custo muito baixo para nós. É preciso mostrar ainda que estamos vinculados a sua miséria a posto de termos uma real responsabilidade, se permitimos que isso continue ocorrendo, pela condição em que se encontram.

A exigência de tal conexão é controversa. Alguns acreditam que o mero fato da desigualdade radical pode fundamentar um apelo à justiça. Pode-se definir "desigualdade radical" por referência a cinco elementos. Primeiro, aqueles que se encontram na posição inferior sofiem de pesadas privaçōes em termos absolutos. Segundo, eles também estão em uma situação muito ruim em termos relativos: os que estão no topo são abastados e encontram-se também em uma situação muito melhor do que os primeiros. Terceiro, a desigualdade é permanente: para os que estão na posição inferior, é difícil ou impossível melhorar sua sorte; e a maioria dos que estão no topo jamais experimentaram, sequer por alguns meses, a vida na posição mais baixa e não têm a mínima idéia do que é viver dessa maneira. Quarto, a desigualdade é generalizada: ela não diz respeito somente a alguns aspectos da vida (tais como o acesso a um clima ameno ou a oportunidades de amor e de satisfação sexual), e sim à maioria deles ou a todos eles. Quinto, a desigualdade é evitável: aqueles que estão no topo podem melhorar as condiçōes dos que se encontram na posiçāo inferior sem que com isso eles mesmos, os primeiros, tornem-se miseráveis.

É evidente que o fenômeno da pobreza global é um exemplo de desigualdade radical tal como foi definida. ${ }^{6}$ Mas não acredito que esses cinco elementos bastan para fundamentar um apelo à justiça (e não apenas um forte apelo ético). E suspeito que a maioria dos cidadåos do Ocidente desenvolvido - aqueles quero convencer - também os achariam insuficientes. Eles endossariam o seguinte raciocínio: suponha-se que amanhã descobríssemos pessoas em Vênus que estão em uma situação ruim, muito pior do que a nossa, e que pudéssemos methorar suas condições sem grandes custos para nós mesmos, o que, entretanto, decidiríamos por não fazer. Uma desigualdade radical persistiria, então, em decorrência de nossa decisão. Mas isso não seria uma injustiça, porque não seríamos responsáveis pela desigualdade radical da mesma forma que o seríamos se a tivéssemos criado ou dela se beneficiado.

${ }^{6} \mathrm{Os}$ quatro primciros pontos são amplamente docunnentados por inúmeras agências c organizaçōes governamentais e não-governamentais. $O$ quinto ponto pde ser substanciado por meio de uma reforma institucional que proporei mais adiante, e também pelos muitos pequenos exitos de proteção, alcançados quando os cidadãos dos países desenvolvidos organizam-se para fornecer sementes, poços, pequenos empréstimos e treinamento básico em alfabetizaçāo, nutrição, higiene, assistência médica, controle de natalidade, marketing, etc... 
Se não basta haver desigualdade radical para se falar em injustiça, o que, então, está faltando? Se (como argumentei) a pobreza global é um exemplo de injustiça, e a hipotética pobreza em Vênus não o é, em que os dois casos diferem?

A seguir, apresentarei três respostas distintas para esse desafio, três visões - com fundamentos filosóficos diferentes e conflitantes - sobre em que consiste a injustiça das instituições econômicas globais vigentes. O sentido desse exercício é revelar dois resultados surpreendentes: concepções de justiça muito divergentes convergem em seu diagnóstico das instituiçőes econômicas globais como injustas. E, apesar divergirem acerca do melhor ideal de longo-prazo, essas concepçốes podem apoiar conjuntamente a mesma alternativa institucional possível, considerando-a significativamente mais justa do que o status quo.

A primeira visão sustenta que um apelo à justiça pode fundamentar-se na privação radical. As pessoas sofrem de privação radical quando, além dos cinco elementos da desigualdade radical, três outros elementos estão presentes. $O$ sexto: aqueles que estão na pior situação e os que estão na melhor coexistem sob um esquema único de instituiçőes, por intermédio do qual há uma significativa e contínua interdependência e uma interação pelo menos indireta entre uns e outros. Sétimo, a desigualdade radical pode ser atribuída a esse esquema institucional: há uma alternativa institucional possível que não geraria essa pobreza extrema e extensiva. E oitavo, a desigualdade radical não pode ser atribuída a fatores extra-sociais, tais como as deficiências genéticas ou os eventos naturais calamitosos.

O caso da pobreza global exemplifica o sexto elemento no sentido de que os pobres globais vivem no contexto de um sistema mundial de Estados baseado em domínios territoriais globalmente reconhecidos e interligados por meio de uma rede internacional de comércio e de diplomacia mundiais; sistema esse $\mathrm{em}$ que os cidadãos dos países desenvolvidos, devido a seu poderio econômico e militar imensamente maior, desfrutam de uma posição de esmagadora dominância política e mediante o qual influenciam dramaticamente as circunstâncias dos pobres via investimentos, empréstimos, ajuda militar, comércio, turismo sexual, exportação de cultura (efeito-demonstração), e muito mais ainda. Uma simples jogada especulativa nos mercados de commodities de Chicago pode significar a diferença entre a vida e a morte para muitas pessoas pobres - como no caso em que o emprego dessas pessoas depende do preço de algum produto exportado no mercado mundial, ou quando o poder de compra de sua renda depende do preço de certos produtos importados no mercado mundial. 
Deve ficar claro, desse exemplo, que a sétima condição pode ser satisfeita sem que exista nada semelhante à exploração dos pobres pelos ricos. Enquanto a exploração supostamente resulta em injustiça, não é preciso haver exploração para haver injustiça, por isso meu argumento neste ensaio não requer e não inclui quaisquer suposiçōes de exploração. Dito isso, acrescento que aqueles que sāo miseráveis em termos absolutos e relativos são também altamente vulneráveis à exploração. $\mathrm{E}$ isso certamente se aplica aos pobres globais: desesperadamente necessitados e sem acesso à educação (e por isso analfabetos e ignorantes das leis e de oportunidades distintas), muitos deles são explorados de forma bastante direta (em modalidades de trabalho compulsório, por exemplo) e obrigados a trabalhar por quase toda sua vida produtiva, submetidos à servidăo e a condiçốes prejudiciais e perigosas, em fazendas, em prostíbulos ou no serviço doméstico.

A pobreza global exemplifica o sétimo elemento, como mostrarei na seção IV. E também exemplifica o oitavo elemento, no sentido de que os pobres globais, se tivessem nascido em circunstâncias sociais diferentes, seriam tăo capazes, e teriam a mesma probabilidade, de levar vidas saudáveis, felizes e produtivas, quanto o restante de nós. A causa fundamental de seu sofrimento é sua chocante posição social inicial, incluindo o contex to social em que nascem, que nâo lhes dá muita oportunidade de serem outra coisa que não pobres, vulneráveis e dependentes - incapazes que são de oferecerem a seus filhos um ponto de partida melhor do que aquele que eles próprios tiveram.

Quando esses três outros elementos estâo presentes, então faz. sentido considerar radicalmente despossuídos aqueles que se encontram em uma situação muito ruim em termos absolutos e relativos. A palavra "despossuídos" indica que essas pessoas não somente não têm o que necessitam para levar uma vida humana plena mas também são privadas do que necessitam pela ação humana. Essas pessoas não são somente pobres e com frequiência famintas, e sim são empobrecidas e levadas a passar fome por nossos arranjos institucionais comuns, que inescapavelmente conformam suas vidas. Elas são privadas do que necessitam, em última análise, por nós, os participantes mais poderosos e mais privilegiados da estrutura de instituições econômicas globais, porque somos nós que lhes impomos essa estrutura, ao invés de uma alternativa institucional que não produziria tal pobreza extrema e generalizada.

A expressão "privação radical" explicita, então, porque a pobreza global reveste-se da forte urgência moral que associamos a um apelo à justiça, e porque devemos encará-la com muito mais gravidade do que um sofrimento, de resto similar, originário de deficiências genéticas, acidentes ou 
vício (ou do que um sofrimento que não pode ser atribufda à interdependência). A razão disso está em que a distribuição de posiçôes sociais em qualquer sistema social é significativamente influenciada pela forma de organização desse sistema, por suas normas fundamentais e instituiçôes sociais, que criamos, moldanos e às quais damos apoio, e que por isso podemos também modificar mediante reformas institucionais. É fácil perder isso de vista, porque muitas vezes percebemos essas estruturas institucionais como naturais. Sentimo-nos felizardos por termos nascido saudáveis e afluentes, ou infelizes por termos nascido com deficiênciaś genéticas ou na pobreza. Esse paralelo pode funcionar para as posiçōes das pessoas em una dada distribuição, mas não para as próprias distribuições. Pois enquanto somos coletivamente capazes de alterar a distribuiçāo de encargos e benefícios sociais reformando as instituiçôes de qualquer sistema social do qual sejamos participantes, não há uma forma razoável de colocar a distribuição de dotaçōes genéticas sob controle humano - pelo menos por enquanto. ${ }^{7}$

De acordo com a primeira visão, poderíamos apelar à justiça em benefício dos pobres globais com base no seguinte argumento:

(1) É moralmente lamentável (ceteris paribus) que as nossas instituições sociais produzam privaçōes radicais. Temos uma razão moral pro tanto para evitar essas privações por meio de reformas institucionais. Essa razão pode não ser decisiva. Mas as instituiçōes que produzem privações radicais necessitam de justificação: há um ônus da prova que recai sobre aqueles que querem defendê-las como compatíveis com a justiça e que vêem sua imposiçăo (e perpetuação) por nós como algo moralmente permissível;

(2) semelhante defesa teria que mostrar que qualquer alternativa proposta à estrutura institucional existente ou (2a) não seria possível (i.e., não seria atingível de onde nos encontramos e não seria suscetível de sustentação estável ao longo do tempo); (2b) não seria preferível com respeito à pri-

7 Uma forma razoável: ainda que para moldar essa distribuiçăo nẩo fosse preciso recorrer a esterilizaçöes forçadas e a campos de externínio, é de se presumir que exiguisse o controle em larga escala da educaçito dos humanos (algo que, em pequena escala, os nazistas colocaram em prática em seu programa "Lesbensborn") - o que dificilmente é uma opçăo moralmente atraente. Poder-se-ia impor, ou oferecer fortes incentivos para isso, o aborto no caso de fetos considerados geneticamente deficientes com base em diagnósticos pré-natais. Mas taunbêm essa opçăo é moralmente viável somente nos casos - relativamente escassos - muitos graves. Por enquanto: é bem possível que os avanços da biotecnologia venham a permitir, en um futuro próximo, erradicar as deficiências genéticas e influenciar a distribuição de dotaçöes genćticas de formas moralmente aceitáveis. 
vação radical, ou (2c) teria outras desvantagens moralmente significativas que contrapesariam quaisquer ganhos com respeito à privação radical;

(3) nossa estrutura institucional global produz a privação radical em larga escala e, por isso, de acordo com (1), necessita de justificação;

(4) há pelo menos uma alternativa institucional que é possível, que seria muito preferível à privação radical e que nāo teria desvantagens moralmente significativas em comparação ao status quo;

(5) portanto, a estrutura institucional vigente é injusta. E temos uma razão moral para reformá-la em direção à alternativa institucional, a menos que outra direção (moralmente superior ou mais viável) à reforma institucional global possa ser especificada.

Apesar de a maior parte desse argumento ser bastante simples, teremos que examinar melhor as premissas-chave (1) e (4). Discutirei a premissa moral (1) juntamente com as duas outras visões a respeito dos padrōes mais rigorosos que um apelo à justiça deve satisfazer. Na seçāo IV, voltarei à crucial premissa empírica (4).

\section{III}

Talvez a premissa (1) possa ser melhor defendida mostrando-se como ela é fraca em três aspectos. Primeiro, ela só se aplica onde há privação, i.e., miséria e inferioridade produzidas por' nossas instituições sociais - que, afinal de contas, são criações humanas: elas são mantidas, alteradas e impostas por seres humanos. Segundo, é preciso que haja uma privação radical, caracterizada, de uma forma bastante estrita, pelos sofrimentos agudos e contínuos vividos por aqueles que se encontram na extremidade inferior de uma desigualdade imensa e penetrante. E terceiro, a premissa (1) não exclui a priori as instituições sociais que produzem uına privação radical - ela somente atribui um ônus da prova, i.e., requer que essas instituiçöes sejam justificados. Devemos ser capazes de defender essas instituiçōes, sobretudo àos radicalmente despossuídos. ${ }^{8}$

A despeito de ser pouco exigente, a premissa (1) não encontra uma aceitação universal, razão pela qual devemos examinar se é possível

8 A premissa (2) indica como deve ser, em termos gerais, uma defesa desse tipo. 
restringi-la de forma a torná-la mais persuasiva sem que ela perca sua capacidade de fundamentar um apelo à justiça $\mathrm{em}$ benefício dos pobres globais. $\mathrm{O}$ que podemos dizer àqueles que acreditam que não é injusto impor instituiçōes econômicas que geram uma privação radical em larga escala, mesmo no caso de haver alternativas institucionais factíveis que não o fariam?

A segunda visão vê a injustiça das instituições econômicas vigentes no fato de que não levam adequadamente em conta os efeitos de graves injustiças cometidas no passado. A condição atual dos pobres globais é significativamente determinada por um dramático período de conquista e de colonização, marcado pela opressão extrema, pela escravidão e até mesmo pelo genocídio, por meio dos quais as instituições nativas dos quatro continentes foram destruídas ou pelo menos severamente abaladas. É claro que não somos responsáveis por essas injustiças passadas. Mas é difícil negar que a riqueza e a posição de dominância global que hoje desfrutamos resultam, em certa medida, do que ocorreu naquele período. É difícil negar que a expulsão e o genocídio dos peles-vermelhas precisa desempenhar um papel de relevo em qualquer explicação causal plausível da afluência comparativa da maioria dos cidadåos norte-americanos hoje. Do mesmo modo, é difícil perceber como a extensão e a severidade incríveis da pobreza global de hoje poderiam ser explicadas sem referência ao vasto impacto da expansão militar européia.

Idealmente, é possível que se desejasse neutralizar os efeitos dessas injustiças históricas calculando as transferências de recursos de e para determinados indivíduos com base em informação histórica precisa e em interpolações hipotéticas. Mas obviamente isso não é possível, nem mesmo remotamente. Pois a maioria de nós, ou todos nós, da geração presente nem sequer teríamos nascido se o século XIX tivesse sido muito diferente do que foi. Também não dispomos de informação histórica precisa sobre os que sofreram injustiças no passado e só temos evidências muito tênues com base nas quais fundamentar as interpolaçőes hipotéticas (por exemplo, sobre o que a sua tataravó teria se tornado se ela não tivesse sido trazida aos Estados Unidos em um navio negreiro). Mas mesmo assim podemos endossar a idéia de que não se deveria permitir que uma história profundamente infamada moralmente resulte em privação radical. Talvez não vejamos nenhuma injustiça em instituições econômicas que regular e previsivelmente produzem uma implacável pobreza em larga escala, desde que as "regras do jogo" sejam corretamente observadas. Ainda assim, é bem possível que rejeitemos essas privaçōes extremas, como moralmente intoleráveis, quando surgiram de interaçōes

${ }^{9}$ Nozick, Robert. Anarchy, State and Utopia. New York, Basic Books, 1974, p. 231. 
em que aquelas regras foram generalizadamente violadas. E então, como Nozick sugere para o caso doméstico, podemos apoiar uma organização das instituiçôes econômicas globais tal que, não produzindo a privaçãoo radical, pelo menos bloqueie os efeitos mais extremos das injustiças históricas. Tal organização é particularmente plausível se a privaçāo radical concentra-se, como é o caso, em sociedades que sucederam àquelas que sofreram crimes internacionais atrozes no passado, enquanto a maior afluência concentra-se nas sociedades que sucederam àquelas que cometeram ou beneficiaram-se desses crimes.

Esse argumento está formulado de forma muito breve, por isso, para prevenir mal-entendidos, permita-me enfatizar duas de suas características. Primeiro, não é um argumento em prol de reparaçōes. A idéia nãoé a de que devemos pagar por crimes passados, que, afinal de contas, foram cometidos por outros, e sim a de que não deveríamos ser tão privilegiados, enquanto outros sofrem tanto, em decorrência desses crimes, que continuam conformando o presente. Segundo, o argumento focaliza pessoas individualmente. Ouve-se freqủentemente que a África, digamos, está hoje tão bem quanto estaria se não tivesse sido colonizada. Essa suposição (obscura e questionável de muitas maneiras) é irrelevante para o argumento, que não focaliza continentes ou sociedades. E é equivocada quando aplicada a pessoas: é certamente falso que aqueles que hoje são desesperadamente pobres na África teriam se tornado, se a África nunca tivesse sido colonizada, igualmente pobres. Talvez outras pessoas, e mesmo muitas outras, teriam se tornado desesperadamente pobres no lugar delas. Mas isso, com certeza, não mostra que aqueles que hoje são desesperadamente pobres, ao final de um processo histórico em que a colonização e a escravidão desempenharam um papel fundamental, não tenham razôes válidas para reclamar. ${ }^{10}$ Eles podem fazer um apelo à justiça que satisfaz um padräo ainda mais exigente do que o satisfeito pelo primeiro argumento: as instituições econômicas globais vigentes não somente geram a privação radical mas também a geram para pessoas cujas posiçōes iniciais thes foram preparadas (assim como as nossas, enormennente privilegiadas, o foram para nós) por um processo histórico profundamente impregnado de crimes das piores espécies.

A terceira visão vê a injustiça das instituiçöes econômicas vigentes na apropriação altamente desigual da riqueza de nosso planeta. As

10 Também vale a pena refletir sobre a suposição inversa: a de que nosso ponto de partida hojé é tăo bom quanto teria sido se nāo tivesse havido colonialismo, escravidtio e genocídio dos indios. Ainda que acreditemos que os habilantes da Europa estariam em uma boa situaçảo hoje (ao final dessa hipotética história isenta de crimes), é difícil compreender como isso poderia conferir a nós (europeus ou norte-ancricanos) as vantagens e os privilégios que hoje desfrutamos. 
pessoas afluentes hoje empregam e consomem imensamente mais dos recursos do planeta (dos minerais, ar, água, terras produtivas, etc.) do que os muito pobres, e elas fazem isso sem nenhuma compensação a estes últimos pela oligopolização do estoque comum. É verdade que os afluentes muitas vezes pagam pelos recursos que usan (o petróleo importado, por exemplo). Mas esses pagamentos vão para outras pessoas também afluentes, tais como os sauditas ou a cleptocracia nigeriana, sendo que quase nada disso pinga para os pobres globais. Por que os diferentes segmentos dos ricos globais teriam o direito de utilizar os recursos naturais do planeta em termos mutuamente agradáveis, deixando outros, sobretudo a maioria dos pobres globais, de fora dos benefícios disso?

John Locke e Robert Nozick desenvolveram concepções de justiça que defendęm a apropriaçåo unilateral dos recursos comuns e o subsequiente direito de se dispor do que foi adquirido da forma como se achar melhor. ${ }^{11}$ Eles consideram que aqueles que legitimamente apossaram-se da América do Norte, digamos, têm o direito de fazer o que quiserem com toda sua riqueza natural. Mas essa suposição, ainda que fosse verdadeira, não ajuda a justificar o status quo. Uma razão é a de que as apropriações relevantes năo satisfazem nem mesmo a condições mínimas de legitimidade, tais como a ausência de coerção e fraude, que tanto Locke quanto Nozick enfatizam. A distribuição atual dos territórios nacionais e de seus recursos é o resultado da mesma história violenta e movida a crimes que a segunda visão trouxe a nossa consideração. Uma outra razão é a de que tanto Locke quanto Nozick acrescentam a importante condição de acordo com a qual os apropriadores devem sempre deixar "o suficiente, e tão bom quanto, para outros", ou então deixar os outros em tão boa situação quanto estariam se a apropriação não tivesse ocorrido. ${ }^{12}$ Essa condiçăo não é satisfeita: os pobres globais estão em pior situação no sentido de que não lhes restou nada para apropriar. É verdade que eles poderiam comprar os recursos naturais no mercado mundial da mesma forma que os afluentes fazem. Mas, dada a grande demanda de recursos naturais por parte das sociedades desenvolvidas, os preços de mercado dos recursos naturais são tais que os pobres não dispõem do poder de compra necessário para se assegurar de algo como um quinhão proporcional (com o qual eles teriam uma possibilidade muito maior de tirarem a si mesmos da miséria). Eles são, assim, efetivamente excluídos: condenados a assistir impotentemente

11 Um as pecto importante da apropriação unilateral em nosso mundo e, evidentemente, o direito universalmente reconhecido de os Estados excluírem os estrangeiros de scu território. O cumprimento desse direito desernpenha um importante papel na privação dos pobres globais.

${ }^{12}$ Locke, John. Segundo Tratado, parag. 27, 33; Nozick, op. cit., pp. 175-177 e cap. IV. 
à distribuição dos abundantes recursos naturais do planeta entre os afluentes, enquanto muitos deles (dos primeiros) estão em uma situação tão ruim, economicamente, quanto é possível a um ser humano estar e ainda permanecer vivo.

Um outro ponto é o de que uma teoria lockeana năo tem uma resposta plausível para a utilização de recursos, crescentemente importante, que não retira do, e sim acrescenta ao, planeta. Os poluidores não degradam pedaços delimitados de ar ou de água, dos quais pudessem ter legitimamente se apropriado de forma unilateral. $\mathrm{O}$ que cada poluidor faz é degradar toda a água e todo o ar do planeta, que são de uso comum, de tal forma que o que resta deles, apesar de ainda ser suficiente, nunca é tão bom quanto fora. Uma vez mais, são os afluentes (incluindo aqui as "elites" do Terceiro Mundo) que produzem uma parte imensamente desproporcional da poluição global, e pode ocorrer que, para eles, os benefícios da poluição superem seus custos. Mas isso não se aplica aos pobres globais: apesar de serem quase que totalmente excluídos dos benefícios, eles mesmo assim assumem uma parcela plenamente proporcional dos custos da poluição. De fato, o custo real da poluiçăo para eles é maior do que para nós, por năo disporem de informaçāo sobre a natureza e os efeitos psicológicos da poluição, nem de acesso aos meios de autoproteção. Nós podemos nos dar ao luxo de ficar dentro de casa, comprar protetores solares e filtros de água, ajustar nossas rotinas nutricionais, recorrer a check-up médicos e a tratamentos para males causados pela poluição. Eles não.

Com a terceira visão à disposição, podemos restringir ainda mais a premissa (1), de modo que ela se aplique somente a instituições econômicas que, em decorrência de crimes internacionais de larga escala, geram a privação de muitas pessoas que estão quase que totalmente excluídas dos benefícios dos recursos planetários. A partir dessa premissa moral básica ainda mais restrita, o argumento pode ter um apelo mais amplo, alcançando qualquer um que defenda pelo menos uma das três visões que discuti. E essa restrição não é danosa ao nosso tópico da pobreza global: mesmo com o seu alcance muito limitado, a premissa (1) ainda se aplica a nossas instituições econômicas globais e, assim, permite que o restante do argumento seja apresentado como um apelo extremamente rigoroso à justiça.

As primeiras duas visões sugerem um imperativo institucional um tanto genérico com respeito à pobreza global: devemos apoiar as reformas institucionais que, melhorando as condições dos pobres globais, levariam a uma redução da privação radical. Pode-se conceber tantas alternativas institucionais quantas caibam nessa descrição geral. A terceira visão estreita o 
campo sugerindo uma idéia mais específica: as instituições econômicas globais devem ser organizadas de forma a que aqueles que empregam mais extensivamente os recursos de nosso planeta (aproximadamente, os mais afluentes) compensem aqueles que (devido principalmente a sua pobreza) fazem pouco uso desses recursos. Essa idéia não exige que consideremos os recursos do planeta como a herança comum da humanidade, para entāo concluirmos que eles deveriam ser controlados por meio de um processo democrático global e distribuídos entre todos os membros da espécie humana. A idéia pode ter uma formulação muito mais modesta, que é tudo de que necessitarei para esboçar a direção que a reforma deve tomar.

A modéstia é importante, porque é preciso que a alternativa institucional proposta seja praticável - suscetível de se sustentar no mundo tal como o conhecemos; e realista - suscetível de conquistar apoio nos países desenvolvidos. Espero que o Dividendo Global de Recursos, ou DGR, a alternativa que será proposta na próxima seção, satisfaça essas duas aspirações, permanecendo próxima dos arranjos institucionais hoje existentes e correspondendo de forma clara aos anseios morais implícitos nas três visões sobre a fundamentação dos apelos à justiça.

\section{IV}

A proposta do DGR aceita - ainda que eu tenha colocado isso em questăo outro lugar ${ }^{13}$ - o sistema de Estados e o controle que os Estados nacionais exercem sobre as pessoas e os recursos que se encontram em seu território. A única modificação que proponho é a de que os Estados não tenham plenos direitos libertarianos de propriedade sobre os recursos naturais em seu território, e que se possa exigir deles que dividam uma pequena parte do valor de quaisquer recursos que decidam utilizar ou vender. ${ }^{14}$ Denomino esse pagamento "dividendo", porque esse termo adequase melhor à terceira visão (explicitada acima) e também porque não tem algumas das conotações odiosas dos termos "imposto" e "taxa". 15 Acredito que a proposta merece ser seriamente considerada, sem passionalidade

13 Nas đuas publicaçōes citadas tun nota 4.

14 Note o contraste com a idéia muito ntais mdical de que, em um enfoque lockeano, "cada indivíduo tem um direito a uma parcela igual dos meios de produçio năo-humanos búsicos" (i. e., os meios de produçĩo, excluindo-se a força de trabalho, que nāo stio produzidos: os recursos no sentido do meu DRG), tal como formulada por Hillel Steiner em "The Natural Right to the Means of Production" (Philosophical Quartely 27, 1977, pp. 41-9) e levada adiante por G.A. Cohen em "Self-Ownership, World Ownership, and Equality: Part II" (Social Philosophy and Policy 3, 1986, pp. 77.96).

15 O que vem a seguir se vale da seçîo I de meu "An Eqalitarian Law of Peoples", em que utilizei a expressão "Imposto sobre os Recursos Globais". 
ou preconceito. A palavra "dividendo" tem o fito de sugerir que a humanidade como um todo tem uma participação inalienável em todos os recursos naturais escassos. De forma similar à posse de ações preferenciais, essa participaçăo năo confere nenhum controle sobre como os recursos naturais deverão ser usados $\mathrm{e}$, por isso, em nada interfere no controle nacional desses recursos. Mas a participação minoritária tem direito a uma parcela dos benefícios econômicos advindos do uso do recur'so em questão, uma vez que a decisão de utilizá-lo e tomada. Os sauditas, por exempló, continuariam a ter o controle total sobre suas reservas de petróleo cru. Não se exigiria deles que extraíssem, ou que permitissem a outros fazê-lo, o petróleo. Mas se decidissem fazê-lo, para o uso próprio ou para a exportação, seria exigido deles o pagamento de um dividendo proporcional ao petróleo extraído. Essa idéia poderia ser estendida aos recur'sos limitados que não são destruídos, mas somente erodidos ou desgastados pelo uso, tais como o ar e a água utilizados na descarga de poluentes ou o solo fértil utilizado na agricultura e na pecuária. $\mathrm{O}$ dividendo poderia ser aplicado mesmo no caso do uso de recursos limitados que podem ser reutilizados indefinidamente sem deterioração (os metais), mas é ́bvio que uma única cobrança no momento da extração é muito menos tedioso $\mathrm{c}$ complicado. ${ }^{16}$

Os Estados nacionais seriam responsáveis pelo pagamento do DGR. Com os sistemas nacionais de arrecadação de impostos já montados, não haveria a necessidade de desenvolver novas capacidades administrativas. Uma vez que é relativamente fácil quantificar as atividades extrativas e poluidoras, o problema da confiabilidade seria tratável e os custos totais de arrecadação poderiam ser pequenos.

O DGR coletado seria empregado na emancipação dos pobres globais de hoje e do futuro: para assegurar que todos tivessem acesso à educação, à assistência médica e aos meios de produção (terra) e/ou a empregos na medida necessária para capacitá-los a satisfazer suas necessidades básicas com dignidade e a representar seus direitos e interesses de uma forma efetiva perante o resto da humanidade (seus compatriotas ou estrangeiros). Em um mundo ideal de sociedades razoavelmente justas e bem-ordenadas, os pagamentos de DGR poderiam ser feitos diretamente aos governos das sociedades mais pobres, com base nas rendas per capita (convertidas segundo paridades de poder de compra) e no tamanho da po-

$16 \mathrm{Na}$ fase de implementaçăo do DGR, uma cobrança única parece ser preferível taumbém no caso dos recursos limitados que antes eram extraídos sem o pagamento do dividendo (por exemplo, os metais que hoje estäo em uso no mundo todo). Somente no caso do uso da terra faz sentido a exigência de um dividendo anual relativo ao mesmo recurso. 
pulação. Essas informaçōes estão facilmente disponíveis e são de monitoramento simples - informaçöes confiáveis e detalhadas são regularmente coletadas pelo Programa de Desenvolvimento das Nações Unidas, pelo Banco Mundial, pelo FMI e por várias outras organizaçōes. ${ }^{17}$

Os pagamentos de DGR possibilitariam aos governos dos países pobres manter níveis mais baixos de taxação, isençōes fiscais mais elevadas e gastos domésticos mais elevados em educação, assistência médica, pequenos empréstimos e infra-estrutura do que de outra forma seria possível tudo isso objetivando especificamente a erradicação da privação radical. $\mathrm{Na}$ medida em que esses governos de fato fizessem isso, o esquema do DGR como um todo não exigiria uma burocracia central, e certamente nada semelhante a um governo mundial, uma vez que os governos simplesmente transfeririam os recursos do DGR uns aos outros por intermédio de uma organização facilitadora, tal como o Banco Mundial, talvez, ou então a ONU. As diferenças em relaçấo aos auxílios tradicionais ao desenvolvimento são: os pagamentos seriam uma questão de direito e não de caridade; e não haveria - não havendo uma correlação entre "doadores" e beneficiários - nenhuma condicionalidade referente à prestaçăo de favores políticos ou econômicos a um doador, ou referente à adoção das instituiçōes políticas ou econômicas preferidas pelo doador. ${ }^{18}$ É claro que a aceitação das transferências de DGR seria voluntária: uma sociedade justa pode evitar uma afluência maior se, democraticamente, ela escolhe fazê-lo.

Em um mundo não-ideal como o nosso, os governos corruptos de Estados pobres colocam um problema importante. Esses governos podem, por exemplo, ter uma propensão a recorrer aos fundos do DGR para garantir os serviços indispensáveis, reservando-se os recursos fiscais domésticos poupados para o uso pessoal dos governantes. Um governo que aja dessa forma não tem direito aos fundos do DGR. Em casos desse tipo, ainda assim é possível encontrar outras formas de gastar os fundos para os quais os pobres do país em questão são beneficiáveis: fazendo-se transferências em dinheiro diretamente aos pobre locais ou a suas organizações,

17 Poder-se-ia supor que a distribuiçĩo doméstica da renda também deveria ser levada em conta. Mesmo no caso de dois países que têm a mesma renda per capita, os pobres de um podem estar em uma situaçăo muito pior do que os pobres do outro. O problema de levar esse fato em conta reside na criação de um incentivo perverso para os governos negligenciarem os pobres de seus países, objetivando a obtençăo de transferências mạiores de DGR. Esse incentivo é ruin porque os govemos podem agir com base nele, e também porque pode-se supor, falsa ou corretamente, que os governos agem com base nele (problemas de aparência e de confiabilidade).

18 Para uma explicaçĩo detalhada de porque esses fatores, e a busca de resultados "visíveis", tornarn o auxilio hoje existente altamente ineficiente, se não inútil, ver a matéria de capa do The Economist, "Why Aid is an Empty Promise", de 7 de maio de 1994. 
ou financiando-se programas de desenvolvimento administrados por agências da ONU (PDNU, WHO, UNICEF, etc.) ou por organizaçőes nãogovernamentais apropriadas (a Oxfam, por exemplo). Quando, em casos extremos, os fundos do DGR não poderiam ser utilizados de forma efetiva para reduzir a pobreza em um determinado país, então não haveria razão para gastá-los lá. Eles deveriam ser gastos onde esses recursos poderiam fazer alguma diferença na redução da pobreza.

No que se refere à elegibilidade aos fundos do DGR, são quatro, então, as possibilidades que se apresentam a um paf́s suficientemente pobre em termos agregados: seus cidadãos mais pobres podem beneficiar-se por intermédio do governo, mediante transferências diretas feitas a eles, por meio de programas de desenvolvimento de outras agências ou podem não se beneficiar de modo algum. Combinações, é claro, são possíveis. (Os pobres de um país podem receber $60 \%$ dos fundos do DGR aos quais fazem jus, um terço disso por meio do governo e dois terços por meio de outros canais.) Como se deve decidir tais questōes? E por quem? As decisões devem ser tomadas pela organização facilitadora, mas segundo regras gerais claras e simples. Essas regras devem ser formuladas, e possivelmente revisadas, por um grupo internacional de economistas e juristas. Sua tarefa é a de conceber essas normas de forma que, a longo prazo, o esquema do DGR como um todo tenha o máximo de impacto positivo sobre as pessoas mais pobres - digamos, sobre o quintil mais pobre. A qualificação "a longo prazo" indica que os efeitos sobre os incentivos devem ser levados em conta. Os governos e os estratos superiores da sociedade estão em posiçăo de se beneficiar dos gastos do DGR de várias maneiras ("trickle-up"), e, por isso, têm um incentivo para assegurar que os fundos do DGR não sejam cortados. As normas devem ser concebidas de modo a tirar partido desse incentivo. Deve ficar claro para os membros da elite econômica e política dos países beneficiáveis que, se querem que sua sociedade receba os fundos do DGR, eles deverăo cooperar para fazer com que esses fundos efetivamente melhorem as oportunidades e o padrão de vida dos pobres.

É possível que, em alguns dos países beneficiáveis pelo DGR, existam facções da elite dirigente para as quais esses incentivos seriam superados pelo interesse em manter 0 s pobres analfabetos, impotentes e dependentes. Ainda assim, os incentivos alterarảo o equilíbrio de forças na direção da reforma: as reformas serão tentadas mais vigorosamente, e em um número maior de países, e serão realizadas mais freqüente e rapidamente do que do contrário seria o caso.

A especificação de como os fundos do DGR devem ser levantados apresenta alguns problemas complexos, dos quais menciono quatro. 
Primeiro, fixar o dividendo em um nível muito elevado pode desencorajar a atividade econômica -- no limite, a ponto de fazer declinar a arrecadação do dividendo. Deve-se notar, entretanto, que os fundos arrecadados pelo sistema do DGR não desapareceriam: eles seriam gastos pelos, e em benefício dos, pobres globais, gerando-se, dessa forma, uma demanda efetiva de mercado que incentivaria a atividade econômica. Segundo, a imposiçăo do DGR sobre a utilizaçāo da terra pode elevar os preços das commodities básicas, o que teria um efeito deletério sobre a posição dos que estão mundialmente em pior situação. Por isso, pode fazer sentido confinar o DGR a terra utilizada para outras finalidades (por exemplo, para a criação de gado ou para a plantação de tabaco, café, cacau ou flores). Terceiro, a fixação dos níveis do dividendo deve levar em conta também os interesses dos que se encontrarão mundialmente pior situados no futuro. O DGR deve ter por alvo a extração de recursos não-renováveis sujeitos a esgotamento dentro de poucas décadas, mais do que os recursos dos quais há uma oferta abundante; e a descarga de poluentes que permanecerão por séculos, de preferência à descarga de poluentes de decomposição mais rápida. Finalmente, enquanto a organização do sistema do DGR é algo inevitavelmente difícil e complicado, é preciso que o próprio dividendo seja facilmente entendido e aplicado. Ele deve se basear em recursos e poluentes cujas extraçāo ou descarga sejam de monitoramento ou estimação razoavelmente simples, garantindo-se assim que cada sociedade pague sua parcela eqüitativa e também que todos possam se certificar disso.

A idéia geral que está por trás dessas observações rápidas é a de que as responsabilidades do DGR devem ser direcionadas para otimizar seus efeitos colaterais. O que talvez surpreenda é que, em seu conjunto, esses efeitos podem ser positivos, devido aos consideráveis benefícios do DGR para a proteção e conservação ambientais. É difícil produzir esses benefícios de uma forma menos pactuada, devido aos problemas familiares de ação coletiva: cada sociedade tem pouco incentivo para restringir seu consumo e sua poluição porque o custo (de oportunidade) de fazê-lo recai sobre ela somente, enquanto os custos do consumo, resultantes da poluiçăo e do esgotamento dos recursos naturais, distribuem-se em escala global (e também pelo futuro).

O que dizer da magnitude total do DGR? Diante da vastidão da pobreza global hoje, pode-se supor que seria necessário um DGR gigantesco para eliminar a privação radical. Não acredito, entretanto, que seja esse o caso. As desigualdades vigentes são o resultado cumulativo de décadas e séculos ao longo dos quais as sociedades mais desenvolvidas recorreram a suas vantagens em termos de capital e de conhecimento para expandir ainda mais essas vantagens. $\mathrm{O}$ que essas desigualdades mostram, muito mais 
do que as fortíssimas tendências centrífugas do mercado mundial, é o poder de um composto de longa existência. É possível que mesmo um DGR pequeno seja suficiente para contrabalançar essas tendências centrífugas dos mercados, pelo menos ao ponto de evitar o surgimento da pobreza extrema e para manter em equilibrio um perfil distributivo global que evite a privação radical.

Eu não posso passar aqui por todas as complexidades envolvidas na determinação da magnitude apropriada do esquema do DGR. Para concretizar um pouco mais as coisas, entretanto, vamos dizer, um tanto arbitrariamente, que fixemos o DGR em até $1 \%$ do produto mundial - ou menos do que isso, se um nível mais baixo fosse melhor, a longo prazo, para os interesses dos mundialmente mais pobres. Um DGR de $1 \%$ atualmente arrecadaria fundos da ordem de 280 bilhōes de dólares por ano. Esta é uma quantia bastante grande em comparação à renda total do quintil mais pobre do mundo, e, se gasta de uma forma efetiva e adequadamente focalizada, em poucos anos faria uma enorme diferença para os mais pobres. De outra parte, é uma quantia não muito grande para o restante de nós: não somente é inferior ao orçamento anual de defesa dos EUA, mas também muito inferior ao preço de mercado da produção anual de petróleo não-refinado, que gira em torno de 400 bilhōes de dólares ( 60 milhões de barris/dia a 18 dólares o barril).

Demoremo-nos um pouco mais no caso do petróleo e examinemos os possíveis efeitos de um DGR de 2 dólares por bartil sobre a extração do combustível. O dividendo total seria pago pelos "Estados proprietários" nos quais o petróleo é extraído. No caso de a extração do petróleo não estar basicamente sob controle estatal, o governo de um Estado proprietário pode repassar, talvez mediante uma elevação de imposto, o custo do dividendo aos produtores privados de petróleo (na vigência do DGR, os governos não teriam nenhuma razão para criar um subsídio à extração de petroleo em seu território). Os produtores de petróleo, por sua vez, tentariam repassar o custo do dividendo a seus consumidores. Provavelmente, eles não teriam como repassar tudo, porque um aumento do preço do petróleo bruto no mercado mundial de 18 para 20 dólares reduziria a demanda, mesmo que alguns dos potenciais substitutos (o carvão) também subissem de preço: urn preço mais elevado do petróleo ofereceria incentivos para formas mais eficientes de transporte, por exemplo. A redução da demanda, por sua vez, manteria o preço de equilíbrio abaixo dos 20 dólares, de forma que os que possuem e fazem a extração de reservas de petróleo acabariam por assumir parte do ônus do DGR. Desse modo, também reduzir- 
se-ia a arrecadação do DGR sobre o petróleo, que hoje seria da ordem de 44 bilhões de dólares por ano (60 milhões de barris/dia a 2 dólares por barril), para uma quantia mais baixa.

Vimos que urna boa parte do custo do dividendo será repassado, na forma de preços de mercado mais elevados, para os "Estados consumidores" (que, é claro, em alguns casos coincidem com os Estados propriet rios). Parte do DGR sobre o petróleo recairá, por exemplo, sobre os japoneses (que não produzem, mas importam uma grande quantidade de petróleo), mesmo que o dividendo seja efetivamente pago pelos países que possuem as reservas de petróleo e que as exploram. Isso mitiga significativamente a preocupação de que a proposta do DGR pudesse ser arbitrariamente enviesada contra algumas sociedades afluentes, as que são ricas em recur'sos naturais, em favor de outras. Essa preocupaçāo é ainda mais mitigada pelo componente de poluiçăo do DGR (os japoneses pagariam o dividendo sobre as emissónes de seus carros).

Considerando que o Estado consumidor não teria nenhuma razão para compensar, por meio da criação de um subsídio ao consumo, os preços internacionais mais elevados do petróleo bruto, essa elevação dos preços seria, então, repassada aos consumidores individuais, que pagariam cerca de 5 centavos de dólar a mais por galão de gasolina ou de combustível para aquecimento (já que um barril de petróleo corresponde a 42 galőes). ${ }^{19}$ Pelo preço desse níquel a mais, e de uma leve redução nos ganhos daqueles que extraem o petróleo, podemos atingir cerca de um sétimo da arrecadaçäo total do DGR visada. Assim, esse exemplo do petróleo bruto mostra que, surpreendentemente, o objetivo pleno do DGR poderia ser alcançado tendo-se por alvo um número limitado de utilização de recursos - talvez os casos que é desejável desencorajar, tendo em vista a proteção e a conservação ambientais, em benefício de nós mesmos e das futuras geraçōes -, sem que mudanças fundamentais no sistema econômico global sejam necessárias.

Pode-se temer que, ao se tornarem consumidores finais de recursos e de produtos associados à poluição, os pobres globais acabem tendo que pagar, eles mesmos, uma parte do DGR. Entretanto, considerando que os pobres consomem muito menos do que uma parcela proporcional do consumo global, e também que eles receberão muito mais do que uma parcela proporcional da arrecadação do dividendo, vê-se que eles estarão

19 A elevaçāo seria um pouco maior para outros bens ou serviços que empregram derivados do petróleo. Mas, com poucns exceçōes (entre eilas, as passagens aéreas), os aumentos seriam pequenos. A despeito disso, é verdade que em termos gerais o DGR produziria uma leve tendência a afastar nossos estilos de vida de empreendinentos intensivos no uso de recursos e de atividades poluidoras. 
em uma situação muito melhor com a mudança do que sem ela. Mas os pobres estarão sujeitos aos mesmos incentivos à conservaçăo e à proteção ambientais que o restante de nós, e é assim que deve ser. ${ }^{20}$

Pode-se temer ainda que uma parte excessiva do ônus do DGR recaia sobre os pobres dos países desenvolvidos. Essa preocupação é infundada, porque as sociedades afluentes continuariam tendo plena soberania sobre seus sistemas econômicos domésticos. Se querem reduzir a desigualdade doméstica, elas sempre poderão fazê-lo por meio de reformas fiscais, subsídios, incentivos, e assim por diante. Não há razão para supor que as sociedades afluentes optariam por mais (ou por menos) desigualdade interna com o DGR do que sem ele. Mantendo-se o padrão interno de distribuição inalterado, a adoção do DGR tornaria, é claro, os pobres das sociedades ricas ligeiramente mais pobres. Mas essa não pode ser uma razão moral contra a eliminação da injustiça gritante que é a privação radical no Terceiro Mundo. E se alguns dos pobres das sociedades afluentes estiverem eles mesmos entre os radicalmente necessitados? Nesse caso, a culpa deve ser atribuída às instituições econômicas internas, que também necessitam de reforma.

Permita-me concluir esta longa seção com uma observação sobre a terminologia. Mencionei antes porque evito palavras como "ajuda" e "sacrifício", e agora quero acrescentar porque o DGR que estou propondo não deve ser visto como redistributivo. Considerar o DGR um esquema de redistribuição sugere que ele se propõe corrigir uma distribuição inicial que, juntamente com os mecanismos institucionais por ela engendrados, seria mantida intocada. $\mathrm{O}$ que defendo, em contraste, é que devemos considerar as instituições econômicas vigentes injustas; e, por isso, devemos apoiar uma reforma em direção a outros mecanismos institucionais, que engendrariam uma distribuição de benefícios e de encargos tal que se reduziria enormemente, se não mesmo eliminar-se-ia de todo, a necessidade moral de redistribuições corretivas. É verdade que, sob o esquema que proponho, alguns teriam mais e outros teriam menos do que têm hoje. Mas também é verdade que, sob o esquema vigente, alguns de fato têm mais, e outros menos, do que teriam sob o meu esquema. Nenhum dos dois esquemas pode, com base nisso, ser denominado "redistributivo". Também é certo que, sob o sistema que proponho, haveria fundos fluindo de consu-

${ }^{20}$ Considere a seguinte analogia: se taxíssemos a gasolina em mais 50 centavos de dólar por galđ̃o nos EUA, c transferíssemos toda a arrecadação aos 40 c mais pobres na forma de um crédito fiscal, nesse caso os pobres ficariam melhor do que estavam ainda que mantivessem seus hábitos com respeito a dirigir carros. Entretanto, é de se supor que ñ̄o os mantivessem (i.e., que consumissem menos gasolina), o que os deixaria em situaçẵo ainda mais favorável, ao mesmo tempo em que se reduziriam a poluiçăo e o esgotamento das reservas de petróleo. 
midores finais, via os poluidores e possuidores de recursos, para os pobres globais. Mas, mediante esses fluxos, os pobres globais somente receberiam o que lhes é de direito sob o esquema do DGR. Esses fluxos não são mais redistributivos do que o são os fluxos de recursos, via fundos de investimentos, das empresas aos acionistas. ${ }^{2 !}$

\section{V}

Esboçando o DGR já com certo detalhamento, espero ter realizado dois objetivos. O primeiro é o de esclarecer e o de tornar mais familiar a idéia central da premissa (3): a de que pode-se afirmar que um arranjo institucional produz coisas tais como a privação radical. Essa idéia é mais digerível quando aplicada a instituições nacionais. Vimos, recentemente, a substituição de regimes socialistas por capitalistas em vários países da Europa do Leste, e assim pudemos observar como as mudanças institucionais podem trazer alteraçōes dramáticas na distribuição da renda e da riqueza, da educação e da assistência médica, dos direitos e das liberdades, e, por isso, da qualidade de vida.

Curiosamente, a familiaridade com a idéia no nível nacional tornou mais difícil perceber sua aplicação no plano mundial. Diante da pobreza em larga escala, da fome, e dos abusos que ocorrem nos países em desenvolvimento, somos tentados a recorrer às explicaçōes que enfatizam as diferenças de instituições nacionais. E essas explicações certamente desempenham um papel para esclarecer, por exemplo, porque alguns desses países desenvolvem-se tão mais rapidamente do que outros. O que tentei mostrar é que não devemos nos contentar em essas explicações nacionais, c que a estrutura institucional global também desempenha um importante papel na geração da privação global. É difícil perceber isso, devido a pelo menos duas razōes: nunca houve uma mudança de regime econômico no plano global, já que os Estados sempre foram reconhecidos como os proprietários soberanos de "seus" recursos; e as explicações nacionais disponíveis parecem fazer o seu serviço explicativo bastante bem sozinhas. $O$ esboço que apresentei do DGR tem o objetivo de superar essas dificuldades. Trata-se de uma alternativa genuína (ainda que hipotética) à estrutura econômica global vigente. É bbvio que essa alternativa teria que ter efeitos distributivos muito diferentes. Ela também faria diferença com respeito aos tipos de regime nacional que emergiram, e com que freqüência.

21 Para uma discussão mais detalhadas do termo redistribuição e de suas conotações tendenciosas, ver meu Realizing Rawls, op. cit., pp. 32, 34n, 238, $276 \mathrm{c}$ meu "Cosmopolitanism and Sovereignty", op, cit., p.52. 
Isso mostra que os arranjos econômicos globais estão envolvidos na geração da privação radical, e que a fome e a pobreza mundiais não podẹn ser explicadas somente por referência a fatores nacionais.

Meu segundo objetivo, evidentemente, foi o de sustentar a premissa (4). Penso que mostrei que, se o esquema do DGR é praticável, então ele funcionaria muito melhor com respeito à privação radical do que a estrutura institucional vigente. Tentarei agora sustentar esse "se" antecedente.

Pode-se supor que o esquema do DGR simplesmente não funcionará. Uma vez que os fundos levantados por meio do dividendo serão gastos nos países e regiões pobres, a maioria dos Estados mais ricos e poderosos so teria a perder aderindo ao esquema. Os motivos morais que podemos esperar das populaçőes e dos governos desses Estados não serão sempre suficientes para garantir essa adesão. ${ }^{22} \mathrm{E}$ a não-adesão por parte de alguns abalaria a disposição de outros de participar. A instituição do DGR, por isso, requereria outras importantes reformas institucionais, incluindo a criação de mecanismos centralizados de coerção.

Em resposta a isso, estou de acordo que o esquema do DGR deve apoiar-se em sançő́es. Mas as sançốes poderiam ser descentralizadas: a partir do relato da agência facilitadora do fluxo do DGR, de que um país não cumpriu com suas obrigações, seria solicitado de todos os demais países a imposição de taxas sobre as importaçōes do país em questão, e talvez também a imposição de encargos similares sobre suas exportações, equivalentes às obrigações do DGR devidas mais o custo dessas medidas coercitivas. Tais sançőes descentralizadas teriam uma boa probabilidade de desencorajar defeç̧óes de pequena escala. O mundo é hoje, e provavelmente permanecerá, altamente interdependente em termos econômicos; a maioria dos países exportam e importam entre 10 e $50 \%$ de seu produto interno bruto. Nenhum deles se beneficiaria do fechamento do comércio exterior para evitar uma obrigação de DGR de cerca de $1 \%$. E cada um teria razōes para satisfazer voluntariamente sua obrigação de DGR: para manter o controle pleno sobre como os fundos são levantados; para evitar o pagamento de medidas coercitivas; e para evitar a publicidade negativa associada à não-obediência.

Resta ainda o problema de defecções de larga escala, que está intimamente relacionado ao problema de obter a concordância da maioria dos países afluente ao DGR já de início. Existem, é certo, argumentos pragmáticos em favor do DGR, e os delinearei no momento oportuno. Mas de nada adiante supor que esses argumentos sejam suficientes por si mesmos.

22 Pode-se fundamentar cssas suposiçōes apontando-se para o grau de negligêneia de muitos Estados com respeito alo pagamento dos encargos, muito menores, de participaçâo na ONU. 
Os argumentos morais influenciaram antes, e ainda influenciam, o comportamento dos Estados - algo que mesmo muitos realistas admitem, ainda que com pesar. ${ }^{23} \mathrm{~A}$ abolição do tráfico de escravos no século XIX constitui um exemplo dramático disso. A Grä-Bretanha esteve na linha de frente dessa iniciativa, empenhando-se ativamente no cumprimento de uma proibição ao tráfico negreiro como um todo, independentemente da propriedade, bandeira, porto de origem ou destino do navio negreiro. A Grã-Bretanha assumiu todos os custos das medidas de coerção que pôs em prática, sem que disso pudesse esperar quaisquer benefícios significativos - na verdade, sobre ela recaíram ainda os custos de oportunidade na forma de comércio não-realizado, sobretudo com a América Latina. Há, é claro, dezenas de outros exemples menos dramáticos, tais como, por exemplo, os esforços de auxílio à Somália e à Ruanda. ${ }^{24}$ Obviamente, muito mais poderia e deveria ser dito acerca das várias similaridades e diferenças entre esses casos e a reforma proposta do DGR. Mas de momento só quero descartar um obstáculo empírico preliminar, que penso ser poderoso, à suposição de que os governos nunca agem contrariamente ao que consideram servir melhor a seus interesses, ou aos interesses de sua sociedade.

A proposta do DGR está bem posicionada para beneficiar-se do fato de que as razões morais podem produzir efeitos no mundo. Como mostrei em detalhe, essa proposta pode ancorar-se amplamente em várias (e talvez mutuamente incompatíveis) correntes da tradição intelectual ocidental - para sustentar que a maior parte dos encargos do DGR deveria recair, direta ou indiretamente, sobre as pessoas do Ocidente desenvolvido. En particular, reduzindo dramaticamente a privação radical gerada por nossas instituiçōes econômicas globais, o DGR pode encontrar apoio nas tradiçōes do conseqüencialismo progressista e do contrato social. $\mathrm{O}$ dividendo pode ser justificado como uma forma geral de mitigar os efeitos mais dramáticos de graves injustiças históricas que nảo podem ser mitiga-

${ }^{23}$ Niio é casual, acredito, que o realismo político florescev em um momento especifico: na exa da Guerra Fria. Nesse período, os imperativos pragmáticos de vencer eram tẫo absolutamente decisivos que tenderam a obscurecer todas as denais consideraçŏes (incluindo as morais). Nos perfodos em que os Estados sentem-se mais seguros, é muito mais possível que seus governos e populaçóes venham a ser, ou possam ser persuadidos a ser, influenciados por considreraçס̄es morais.

24 Pode-se objetar que os políticos muitas vezes são sensiveis a argumentos morais somente na medicla em que isso melhore a imagem de seu pais ou de seu governo, ou mestro a própria imagem. O que é verdade, mas esse é um ponto que robustece meu argumento. Pois a objoçîio admite que algumas pessous (aquelas que os políticos estăo tentando impressionar) realmente preocupam-se com consideraçōes morais. E isso mostra como a eficácia dessas consideraçס̄es é aumentada por um tipo de efeito multiplicador. 
das de uma forma mais específica. Ele pode ser apoiar-se ainda em argumentos libertarianos, por satisfazer uma condição de restrição razoável à apropriação unilateral. E ele tem também a vantagem, moralmente importante, de alterar o consumo de forma a restringir a poluição e o esgotamento dos recursos globais, em benefício de todos os seres humanos e das geraçōes futuras em particular.

Se essas quatro argumentações morais podem ser adequadamente desenvolvidas e defendidas, a aceitação moral do DGR pode gradualmente emergir e difundir-se pelo Ocidente desenvolvido. É possível que se venha a considerar o esquema do DGR mais justo do que a estrutura da economia mundial hoje vigente.

Alguns entre aqueles que aceitam essa conclusão poderiam ser tentados, mesmo assim, a invocar o valor da parcialidade nacional: é perfeitamente permissível que nós e o nosso governo, em um espírito de solidariedade patriótica, concentremo-nos na promoção dos interesses de nossa sociedade e de nossos compatriotas, ainda que existam estrangeiros em uma situação muito pior. Somente preciso qualificar, e não negar, essa afirmação: a parcialidade somente é legítima no contexto de um esquema justo de competição ou de cooperação. Trata-se de uma idéia familiar e amplamente aceita no caso doméstico. É perfeitamente legítimo que as pessoas concentrem-se na promoção de seus próprios interesses, e nos de seus parentes, desde que o façam em um "campo igual de jogo" cuja justiça substantiva é continuamente preservada. A parcialidade para com a própria família é decididamente inaceitável quando nós, enquanto cidadãos, defrontamo-nos com decisōes políticas nas quais esse próprio campo de jogo está em questão. Seria moralmente errado, por exemplo, mesmo (ou especialmente?) no caso de so se ter meninos brancos como filhos, não se apoiar o acesso igual de negros e mulheres à educação superior. A maioria dos cidadãos no Ocidente desenvolvido entende e aceita esse argumento sem discussão. Também não deveria ser tão difícil fazêlos entender que, por razőes bastante semelhantes, a parcialidade nacional só é moralmente aceitável em condições em que a justiça da competição internacional é continuamente preservada; e fazê-los entender que é moralmente errado os países ocidentais ricos se valerem de um poder de barganha enormemente superior para impor aos pobres globais uma ordem econômica que tende a perpetuar, $\mathrm{c}$ talvez a agravar, suas pobreza extrema e radical inferioridade. ${ }^{25}$

25 Para um argumento distinto, no sentido de que a parcialidade não-qualificada contitui uma falha, ver o meu "Loopholes in Moralities" (Journal of Phitosophy 89, 1992, pp.79-98). 


\section{VI}

Não posso tratar aqui de todas as pré-concepçōes e objeções que podem bloquear um amplo compromisso moral com um DGR. ${ }^{26}$ Mas posso, brevemente e em conclusão, enfrentar a objeçāo pragmática. Deixando-se de lado a moralidade, faz sentido para nós dar apoio a uma reforma institucional que tenderia a futuramente tornar nossas sociedades mais fracas economicamente do que o seriam sem ela, ao mesmo tempo em que beneficiaria as sociedades que, a longo prazo, podem ameaçar a própria sobrevivência de nossos valores e de nossa forma de vida? ${ }^{27}$

Olhando-se para as instituições nacionais, os governos, as culturas, as religiões e as emoçôes hoje prevalentes nos países em desenvolvimento, não é possível sentir tranquilidade com respeito a um futuro em que seus Estados possuirăo as tecnologia avançadas que atualmente possuímos (para não falar das tecnologias ainda mais avançadas que teremos nas próximas décadas). Os progressos tecnologicos oferecem possibilidades cada vez maiores de ocorrência de desastres de grandes proporções, entre os quais os que se associam a armas e acidentes nucleares, químicos ou biológicos são somente os mais dramáticos e 6 bvios. Muitos desses desastres extrapolariam as fronteiras nacionais, e nenhum Estado, ou grupo de Estados, pode proteger-se de todas as deterioraçōes externamente induzidas, sejam elas graduais ou catastroficas, de seu meio ambiente. ${ }^{28}$ Eis aí o ponto: os perigos associados à proliferação tecnologica são inerentes à ordem mundial existente. A Índia e o Paquistão, o Brasil e o Vietnă, a Síria e a Indonésia não estão esperando pelo DGR para iniciar seus próprios esforços para alcançar o Ocidente - eles estão trabalhando duro nisso neste exato momento. Se as tendências atuais persistirem, toda a humanidade, incluindo o ocidente desenvolvido, defrontar-se-á com perigos sem precedentes - ocorrências que såo tanto piores quanto mais

26 Entre as quais, o lugar de maior proeminência talvez caiba aos argumentos do relativismo culturai, segundo os quais a instituição DGR equivaleria à imposiçấo dos valores liberais ocidentais a outras culturas. Tratei dessa questâo cm Realizing Rasws, pp. 267-273, e em "An Egalitariam Law of Peoples".

27 Como uma razão pragnárica em seu favor, poder-se-ia mencionar a de que o DG: beneficiaria ["nós", dos pafses desenvolvido] limitando a poluighto e o esgotamento dos recursos. Mas é provável gue esse benefício possa ser atingido por meios mais econômicos. Poderíamos instittir un dividendo nacional de recursos e tentar induzir outros Estados a fazer o mesmo. Isso poderia envolver algumas transferências residuais a governos de países $\mathrm{cm}$ desenvolvimento - similares às recentes iniciativas de conversão de parte do debito externo de alguns desses países $\mathrm{cm}$ programas de preservação ambiental -, mas essas transferências se. riam consideravelmente inferiores a um DGR de $1 \%$.

28 É preciso explicar por que coisas como o programa "Guerra nas Estrelas" não servem? 
prováveis do que as que enfrentamos durante a Guerra Fria - dentro de poucas décadas.

Apesar de voltados aos pobres, os fundos do DGR teriam efeitos secundários que permitiriam aos países em desenvolvimento beneficiáveis nos alcançar mais rapidamente em tecnologia do que do contrário lhes seria possível. Preservar o status quo, assim, tem a vantagem relativa de adiar um pouco o problema. A proposta do DGR, de outra parte, tem uma vantagem muito maior: ela tem o potencial de se tornar parte de uma solução duradoura. Uma das razóes para isso é a de que o DGR tenderia a expandir a educação (a alfabetização!) e a reduzir a desigualdade sócioeconômica dentro dos países em desenvolvimento beneficiáveis. Dessa forma, a reforma tenderia a tornar esses pafses menos sujeitos a ideologias primitivas e ao autoritarismo. E o que é mais importante, o DGR seria parte de um relaxamento mais amplo da noção de soberania estatal, que está se tornando tão perigosa no mundo moderno. Se o controle final sobre as tecnologias avançadas permanecer territorialmente dividido entre cerca de duzentos governos nacionais, as possibilidades de evitar desastres de grandes proporções serão muito reduzidas. Se os Estados mais poderosos tentarem impor esse controle unilateralmente, eles provavelmente encontrariam uma tenaz resistência a isso e teriam que recorrer à força. Parece ser mais promissor, então, perseguir o mesmo objetivo de forma multilateral, abrandando a noção de soberania estatal de uma forma equilibrada: nós, as sociedades altamente desenvolvidas, abandonamos a pretensäo de que toda nossa enorme afluência somente a nós pertença, e de que seja lícito nos valermos dela, em nossas negociaçóes com o resto do inundo, para exercer pressão no sentido de consolidar e ampliar nossa vantagem. Eles, o restante, abandonam a pretensão de que cada Estado tem o poder soberano de desenvolver e de controlar por si mesmo todas as capacidade tecnológicas que já possuímos. ${ }^{29}$

Esse cenário mostra uma outra razäo para acreditar que um compromisso com o esquema do DGR pode se difundir de forma ampla entre nossos compatriotas do ocidente desenvolvido: também nós, como os pobres globais, temos um forte interesse em uma erosão gradual da doutrina da soberania estatal absoluta, mediante o fortalecimento da preo-

29 Não sou ingênuo a ponto de acreditar que essa proposta seriam bem recebida por todos os países en desenvolvimento, para não falar nos atuais governos desses países. Inplementá-la poderia cxigir sançōes econômicas e até mesmo intervençôes militares. Meu argumento é o de que sua implentaçăo pelo menos seria moral e politicamente viável (supondo-se que estou certo em acreditar que essa proposta poderia conquistar um apoio significativo em muitos países em desenvolvimento), enquaato a instituç̧ĩo unilateral de um regime de eontrole tecnoiógico não seria viável em nenhum desses sentidos. 
cupação com o bem-estar da humanidade como um todo - apesar de que o nosso interesse, de certa forma, é menos imediato do que o deles. Queremos deixar a nossos filhos e netos um mundo em que eles possam se sentir seguros. E a melhor maneira de fazê-lo, acredito, é conquistando as populaçôes e os governos dos países em desenvolvimento para nossa visão de um futuro em que eles desfrutariam de segurança, de respeito, de influência política e de condiçoes materiais suficientes, sem que controlassem seus próprios arsenais nucleares (nem seriam ameaçados pelos de outros) e coisas semelhantes. ${ }^{30}$

Concluo, de forma tentativa, que não é quimérico acreditar que um compromisso generalizado e ativo a um DGR, por parte das sociedades e dos governos mais afluentes, poderia se constituir no mundo tal como o conhecemos. Mas isso só ocorrerá, é claro, se as preocupações com a justiça global, e com o futuro mais distante, puderem ser trazidas para dentro de nossa política.

THOMAS POGGE é professor do Departamento de Filosofia da Columbia University, Estados Unidos.

30 Essa visão se choca, admito, com nossas atuais noçōes de soberania estatal. Ela envolve uma ordem mundial mais demøcrática, um papel maior para as organizaçōes centrais, e nesse sentido, mais governo mundial do que hoje temos (apesar de não envolver nada semelhante a um governo mundial de acordo com o modelo dos govemos nacionais vigentes). Mas, essa visão năo $\in$ parte de minha proposta do DGR. Ela somente descreve o que considero ser o beneficio potencial mais importante do esquerna do DGR. 


\section{UMA PROPOSTA DE REFORMA: UM DIVIDENDO GLOBAL DE RECURSOS}

As privaçồes sofridas pelas pessoas mais pobres dos países pobres devem ser entendidas, não como eventos pelos quais os mundialmente mais privilegiados não têm nenhuma responsabilidade, e sim como injustiças produzidas por uma estrutura institucional comum. A erradicação dessas privaçöes, em consequiência, depende de uma reforma nas instituiçōes (sobretudo econômicas) globais. $\mathrm{O}$ artigo argumenta em favor de uma das propostas de reforma que têm sido discutidas: a introdução de um dividendo global que incidiria sobre a utilização de recursos naturais e 
sobre as atividades poluidoras. Os recursos arrecadados seriam destinados à erradicação da miséria no mundo todo.

\section{A GLOBAL RESOURCES DIVIDEND}

THOMAS POGGE

The world's most privileged can not claim to be free of any responsibility for the deprivation suffered by the poorer of the poor countries. Such deprivation is the result of a common institutional framework, so it ought to be seen as injustice. Therefore, the erradication of radical deprivation depends upon a reform of our global institutions (chiefly the economic ones). Arguments are presented on behalf of one of the current proposals: the introduction of a global dividend to be applied to the use of natural resources and to pollution-led activities. The revenue can then be used to the emancipation of the global poor. 